\title{
CRESCIMENTO E SOBREVIVÊNCIA DE ESPÉCIES ARBÓREAS EM DIFERENTES MODELOS DE PLANTIO NA RECUPERAÇÃO DE ÁREA DEGRADADA POR DISPOSIÇÃO DE RESÍDUOS SÓLIDOS URBANOS ${ }^{1}$
}

\author{
Luana Auxiliadora de Resende ${ }^{2}$, Lilian Vilela Andrade Pinto ${ }^{3}$, Eder Clementino dos Santos ${ }^{4}$ e Sueila \\ Silva ${ }^{5}$
}

\begin{abstract}
RESUMO - Objetivou-se, neste trabalho, avaliar o desenvolvimento silvicultural e a sobrevivência das espécies em diferentes modelos de plantio de mudas para recuperação da área do lixão de Inconfidentes - Sul de Minas Gerais/Brasil, a qual se encontra com deficiência de vegetação, o que proporciona impactos visual e ambiental, com o intuito de indicar diferentes espécies vegetais que possam ser ideais para serem utilizadas na requalificação dos lixões. O experimento foi instalado no delineamento estatístico inteiramente casualizado com quatro modelos de plantio envolvendo mudas de 11 espécies arbóreas nativas e da gramínea Chrysopogon zizanioides (M1Leguminosas; M2- Leguminosas + Chrysopogon zizanioides; M3- nativas e M4- Eremanthus erytropappus e Nectandra lanceolata) e três repetições. As parcelas de $3 \times 5 \mathrm{~m}$ de cada tratamento foram compostas por 15 mudas arbóreas, sendo acrescidas em cada modelo de plantio M2 oito mudas da gramínea Vetiver (C. Zizanioides). Foram avaliados ao longo de 20 meses a altura das plantas, o diâmetro do caule ao nível do solo, a área de copa e a sobrevivência, em intervalos de 30 dias. Os dados do crescimento silvicultural e sobrevivência entre os tratamentos e entre as espécies foram submetidos à análise de variância e as médias, comparadas pelo teste de Scott Knott a 5\% de probabilidade. A partir da análise dos resultados da recuperação da área do desativado Lixão de Inconfidentes - Sul de Minas Gerais/Brasil, conclui-se que o modelo de plantio M2 e as espécies Bauhinia forficata, Eritrina falcata, Senna multijuga, Schizolobium parahyba e Schinus terebinthifolius são as mais indicadas para recuperação da área.
\end{abstract}

Palavras-chave: Lixão; Espécies nativas; Leguminosas arbóreas.

\section{GROWING AND SURVIVAL OF TREE SPECIES IN DIFFERENT PLANTING MODELS ON THE RECOVERY OF AN AREA DEGRADED BY URBAN SOLID WASTES DISPOSAL}

\begin{abstract}
The project goal is to evaluate the silvicultural development and the survival of species in different seedlings planting models for the recovery of the landfill area in Inconfidentes - South of Minas Gerais/ Brazil, which shows lack of vegetation, causing visual and environmental impact. This paper also aims to suggest different species that may be used on the requalification of landfills. This experiment was installed in a completely randomized statistic design with four plantation models and seedlings of 11 native tree species and also a grass species, Chrysopogon zizanioides (M1-Legume; M2-Legume + Chrysopogon zizanioides; M3-native and M4-Eremanthus erytropappus and Nectandra lanceolata) and three repetitions. The plots of $3 \times 5$ m of each treatment were composed by 15 tree seedlings and on each M2 planting model eight seedlings of the Vetiver grass (C. Zizanioides) were added. During 20 months the height of those plants, the trunk diameter on soil level, the canopy area and survival were evaluated in gaps of 30 days. The data about the silvicultural growth and survival among those treatments and among species were submitted to variance analysis and
\end{abstract}

\footnotetext{
${ }^{1}$ Recebido em 05.11.2012 aceito para publicação em 19.11.2014

${ }^{2}$ Instituto Federal de Educação Ciência e Tecnologia do Sul de Minas Gerais, Câmpus Inconfidentes, Graduada em Tecnologia em Gestão Ambiental, Inconfidentes, MG - Brasil. E-mail: <luanaaresende@gmail.com>, <lilian.vilela@ifsuldeminas.edu.br>, <eder.clementino@ifsuldeminas.edu.br>e < sueilaambiental@gmail.com>.
} 
the mean values were compared by the Scott Knott test at a 5\% probability. Based on the results of the recovery of the inactivated landfill area in Inconfidentes - South Minas Gerais/Brazil, it is possible to conclude that the plantation model M2 and the species Bauhinia forficate, Eritrina falcate, Senna multijuga, Schizolobium parahyba and Schinus terebinthifolius are the most indicated species for that area recovery.

Keywords: Landfill; Native species; Leguminous trees.

\section{INTRODUÇÃO}

A intensificação do crescimento populacional, juntamente com as mudanças de hábitos, resultou no aumento gradativo do volume de resíduos sólidos, os quais, muitas vezes, são descartados em área sem prévio tratamento ou fiscalização adequada, a exemplo de lixões, expondo a população a situações adversas que interferem negativamente na qualidade de vida e inibindo qualquer tipo de atividade, inclusive a turística, tanto no próprio local de disposição quanto no entorno dessas áreas.

Constata-se que, com dados da Pesquisa Nacional de Saneamento Básico - PNSB (IBGE, 2008), 50,80\% dos municípios brasileiros dispõem seus Resíduos Sólidos Urbanos (RSU) em áreas vulgarmente conhecidas como lixão. Essas áreas encontram-se degradadas e necessitam da elaboração de um plano de recuperação e revegetação, além do monitoramento ao longo dos anos para avaliar a dinâmica das espécies implantadas e de sucessão da área. Há grande carência de estudos e trabalhos objetivando a recuperação ou a requalificação de locais relativamente degradados por disposição inadequada de RSU, podendo, assim, provocar danos para os recursos naturais água, solo, fauna, flora e, especialmente, para a espécie humana.

Nessas áreas onde se visa à sua recuperação, devese considerar a questão da dificuldade relacionada ao fato de que o solo que cobre o lixo não possui a estrutura primária, ou seja, a falta de solo de superfície e a deficiência de nutrientes, que pode afetar diretamente o estabelecimento e crescimento de plantas. Ainda, deve-se destacar que esses solos se apresentam, na maioria das vezes, compactados, podendo, segundo Ferreira et al. (2010), comprometer ainda mais o desenvolvimento das plantas.

O plantio de mudas é técnica de recuperação muito utilizada em áreas degradadas que apresentam sua resiliência comprometida. No Brasil, há carência de informações relacionadas à recuperação da vegetação arbórea de áreas de lixões ou aterros controlados, podendo ser citados os trabalhos de Andrade (2000) e Beli et al. (2005). Outros autores como Alberte et al. (2005), Souza (2007), Manhago (2008), Lima et al. (2009) e Londe (2011) relataram a importância do uso de vegetação nessas áreas favorecendo a regeneração natural ou a implantação do consórcio entre gramínea e leguminosas rasteiras .

Nesse aspecto, o objetivo deste trabalho foi avaliar o desenvolvimento silvicultural e a sobrevivência das espécies em diferentes modelos de plantio de mudas para a recuperação da área do lixão de Inconfidentes - Sul de Minas Gerais/Brasil.

\section{MATERIAL E MÉTODOS}

\section{1. Área de estudo e caracterização do experimento}

Em novembro de 2009, deu-se início ao experimento de revegetação de parte da área do "lixão" da cidade de Inconfidentes, MG, a qual se encontrava desativada, por técnica de regeneração artificial a partir do plantio de mudas em diferentes combinações de espécies (modelos de plantio), seguindo o delineamento estatístico inteiramente casualizado com quatro modelos de plantio (M1, M2, M3, M4), descritos a seguir, e três repetições.

- M1 Leguminosas: plantio de mudas de leguminosas arbóreas (Eritrina speciosa, Eritrina falcata, Schizolobium parahyba, Bauhinia forficata e Senna multijuga).

- M2 Leguminosas + Chrysopogon zizanioides: plantio de mudas de leguminosas arbóreas plantadas em M1 consorciadas com a gramínea C. Zizanioides (Vetiver).

- M3 Nativas: plantio de mudas de espécies arbóreas nativas (Solanum pseudoquina, Solanum granulosoleprosum, Lithraea molleoides, Tibouchina sellowiana, Schinus terebinthifolius e Guazumaulmifolia).

- M4 Eremanthus erytropappus e Nectandra lanceolata. 
A área experimental de $315 \mathrm{~m}^{2}$ localiza-se a $899 \mathrm{~m}$ de altitude e apresenta, segundo a classificação de Koëppen, clima tropical úmido ( $\mathrm{Cwb}$ ) com estações chuvosa e seca bem definidas. As parcelas dos modelos de plantio foram de $15 \mathrm{~m}^{2}$ de área útil, tendo bordadura de uma linha de plantio. As mudas foram plantadas seguindo o espaçamento de 1,0 m entre plantas, num total de 15 covas por parcela e 180 mudas de 13 espécies arbóreas. Para o modelo de plantio "M3", a gramínea C. zizanioides foi plantada seguindo o espaçamento de $30 \mathrm{~cm}$ entre as mudas arbóreas, num total de 24 mudas.

A precipitação (Tabela 1) e a fertilidade do solo (Tabela 2) foram monitoradas ao longo do experimento. Já a avaliação da compactação do solo ocorreu em maio de 2010, em seis pontos de amostra, utilizando o penetrômetro de Stolf. A média da resistência à penetração do solo foi de $0,59 \mathrm{Mpa}$ nas camadas superficiais ( 0 a $20 \mathrm{~cm}$ ), valor considerado intermediário segundo USDA (1993) e superior ao encontrado nas camadas mais profundas. Segundo dados da Prefeitura de Inconfidentes, a área foi coberta por cerca de 40 $\mathrm{cm}$ de terra, muito embora durante o coveamento da área nas dimensões de $40 \mathrm{~cm}$ de profundidade e 30 $\mathrm{cm}$ de diâmetro, com o uso de broca acoplada ao trator, tenha-se observado que na maior parte da área o solo se encontrava coberto com apenas $20 \mathrm{~cm}$ de terra, explicando a variação dos valores da compactação ao longo do perfil do solo e comprovando a presença de RSU na área.

\subsection{Avaliações do crescimento das plantas, sobrevivência e análise estatística}

O acompanhamento do desenvolvimento da altura (H) e do diâmetro do caule ao nível do solo (DC) das espécies no campo foi realizado em intervalos de 30 dias após o replantio das mudas, totalizando 20 avaliações. Para avaliação do desenvolvimento das espécies, foi utilizada a diferença do crescimento médio da última medição (20 meses após o plantio), para a primeira medição (um mês após o plantio). Já a sobrevivência das espécies e a área de projeção da copa (AC) foram mensuradas aos 20 meses do replantio. A AC foi determinada realizando duas medições do diâmetro da copa no sentido do eixo cartesiano; em seguida, fez-se a média das medições para obter o valor do diâmetro médio (D) e aplicou-se a fórmula da área $\left(\mathrm{A}=\pi^{*} \mathrm{D}^{2}\right) / 4$.

Os dados dos parâmetros avaliados foram submetidos à análise de variância (ANOVA) e as médias, comparadas pelo teste de Skott-Knott a 5\% de probabilidade. Os gráficos foram gerados no programa Sigma Plot.

Tabela 1 - Precipitação (mm) registrada durante janeiro de 2009 a julho 2011, em Inconfidentes, MG. Table 1 - Precipitation ( $\mathrm{mm}$ ) registered from January/2009 to July/2011 in Inconfidentes, MG.

\begin{tabular}{lccccccccccccc}
\hline Ano/mês & J & F & M & A & M & J & J & A & S & O & N & D \\
\hline $\mathbf{2 0 0 9}$ & 421,7 & 241,7 & 220,2 & 66,7 & 37 & 62,5 & 47,1 & 84,8 & 245,8 & 238,7 & 217,4 & 383,5 \\
$\mathbf{2 0 1 0}$ & 395,9 & 86,5 & 258 & 41,4 & 32,7 & 19,8 & 53,1 & 0,0 & 73 & 51,5 & 114,1 & 270,6 \\
$\mathbf{2 0 1 1}$ & 406,5 & 165,8 & 231 & 69,5 & 9,9 & 51,5 & 0,0 & 27,5 & 13,0 & 198,6 & 188,6 & 209,9 \\
Média & 405 & 164,7 & 236,4 & 59,2 & 26,5 & 44,6 & 33,4 & 37,4 & 110,6 & 180,5 & 173,4 & 288 \\
\hline
\end{tabular}

Fonte: COPASA, 2012.

Source: COPASA, 2012.

Tabela 2 - Análises químicas do solo da área em recuperação do Lixão de Inconfidentes, MG. Table 2 -Chemical analyzes of soil of the landfill recovery area on Inconfidentes, MG.

\begin{tabular}{lcccccccccccc}
\hline Análises & $\mathrm{pH}$ & $* \mathrm{P}$ & $* \mathrm{~K}$ & $* \mathrm{Ca}$ & $* \mathrm{Mg}$ & $* \mathrm{H}+\mathrm{Al}$ & $* \mathrm{Al}$ & $* \mathrm{SB}$ & $* \mathrm{CTC}$ & $\mathrm{V} \%$ & $* * \mathrm{M} . \mathrm{O}$ \\
\hline $\mathbf{1}^{\mathbf{a}}$ (nov.-2009) & 6,58 & 3,9 & 76 & 2,20 & 1,20 & 1,38 & 0,0 & 3,6 & 4,9 & 73,4 & 0,21 \\
$\mathbf{2}^{\text {a }}$ (Nov.-2010) & 6,19 & 8,0 & 76 & 1,4 & 0,70 & 1,61 & 0,0 & 2,3 & 3,9 & 58,8 & 1,08 \\
$\mathbf{3}^{\text {a }}$ (fev.-2011) & 5,82 & 4,8 & 123 & 1,8 & 0,95 & 1,74 & 0,0 & 2,5 & 4,8 & 63,9 & 0,61 \\
$\mathbf{4}^{\mathbf{a}}$ (maio-2011) & 6,42 & 2,1 & 137 & 1,70 & 0,70 & 1,37 & 0,0 & 2,8 & 4,1 & 66,7 & 1,19 \\
$\mathbf{5}^{\text {a }}$ (dez.-2011) & 6,08 & 4,3 & 101 & 0,88 & 0,9 & 1,59 & 0,0 & 2,05 & 3,63 & 55,5 & 1,38 \\
Média & 6,22 & 4,6 & 103 & 1,6 & 0,89 & 1,54 & 0,0 & 2,65 & 4,27 & 63,7 & 0,89 \\
\hline
\end{tabular}

Fonte: IFSULDEMINAS - Campus Inconfidentes, laboratório de análise de solos.

Source: IFSULDEMINAS - Campus Inconfidentes, soil analysis laboratory. 


\section{RESULTADOS}

\subsection{Crescimento e sobrevivência dos modelos de plantio}

A avaliação dos quatro modelos de plantio (M1 Leguminosas, M2 Leguminosas + C. zizanioides, M3 Nativas e M4 E. erytropappus e $N$. lanceolata) em relação ao crescimento em altura $(\mathrm{H})$ (Figura $1 \mathrm{~A}$ ), diâmetro do caule ao nível do solo (DC) (Figura 1B), área de copa (AC) (Figura 1C) e sobrevivência (Figura 1D) mostrou significância do modelo de plantio M4 com relação aos demais, em decorrência da total mortalidade das espécies em M4.

Nos modelos de plantio M1, M2 e M3, não foram observadas diferenças significativas $(\mathrm{P}>005)$ em relação a H (Figura 1A) e AC (Figura 1C), mas diferenças significativas nas variáveis DC (Figura 1B) e sobrevivência (Figura 1D). O modelo de plantio M1 promoveu o crescimento do DC inferior aos demais (Figura 1B), e o modelo de plantio M2 apresentou maior sobrevivência (56,67\%), seguido pelos modelos de plantio M1 e M3, que não diferiram entre si e apresentaram valores de sobrevivência de $29,67 \%$ e $28,33 \%$, respectivamente.

Destaca-se que o modelo de plantio M2 teve significância ao M1 nas variáveis DC (Figura 1B) e sobrevivência (Figura 1D), mesmo tendo sido plantadas as mesmas espécies de leguminosas arbóreas em ambos os modelos de plantio, diferenciando apenas pelo consórcio da gramínea C. zizanioides.

\subsection{Crescimento e sobrevivência das espécies arbóreas nos diferentes modelos de plantio}

Os valores dos parâmetros de crescimento e da sobrevivência demonstraram que as espécies, quando comparadas entre si em diferentes modelos de plantio (M1 e M2) ou quando comparadas dentro do mesmo modelo de plantio (M1, M2 e M3), diferenciam-se estatisticamente $(\mathrm{P}<0,05)$ pelo teste de Skott-Knott (Figura 2).

Observando a Figura 2A-D, verifica-se que as espécies no modelo de plantio M2 (Leguminosas + C. zizanioides) tiveram adaptabilidade superior ao comparar com o modelo de plantio M1, com apenas leguminosas arbóreas. Das espécies de leguminosas arbóreas plantadas nos modelos de plantio M1 e M2, as que se sobressaíram no M2 foram $S$. multijuga, $E$. falcata e S. parahyba (Figura 2A-D).
Destaca-se que, mesmo não apresentando diferença estatística entre os modelos M1 e M2, S. parahyba na sobrevivência(Figura 2D)eE. speciosa naAC e sobrevivência (Figura 2CD) tiveram maiores sucessos em M2. AAC das espécies leguminosas (Figura 2C) teve o desenvolvimento favorecido no modelo de plantio M2, em que apenas a espécie E. speciosa apresentou valor de AC inferior a 2,6 $\mathrm{m}^{2}$. Já B. forficata exibiu melhor crescimento no modelo de plantio M1 (Figura 2A-C) e se destacou na sobrevivência (66,67\%) em M2 (Figura 2D).

Entre as espécies do modelo de plantio M3, a espécie S. terebinthifolius se destacou em todos os parâmetros de crescimento avaliados (H, DC e AC) e na sobrevivência, existindo significância em relação a $L$. molleoide, S. granuloso-leprosum, S. parahyba, G. ulmifolia, T. Sellowiana e L. molleoides (Figura 2E-H). S. terebinthifolius alcançou destaque ainda maior nos parâmetros de crescimento em $\mathrm{H}$ e AC, sendo a única espécie a ultrapassar os $2 \mathrm{~m}$ de $\mathrm{H}$ aos 20 meses do plantio no modelo de plantio M3 (Figura 2E) e a ultrapassar $6 \mathrm{~m}^{2}$ de AC, considerando todos os modelos de plantio (Figura 2CG).

De maneira geral, a sobrevivência das espécies nos modelos de plantio com espécies leguminosas (M1 e M2) foi baixa, inferior a $50 \%$, com exceção da B. forficata, que no modelo de plantio M2 apresentou sobrevivência de $66,67 \%$, valor estatisticamente superior ao das demais espécies no mesmo modelo de plantio (Figura 2D).

Na avaliação da sobrevivência no modelo de plantio M3, as espécies G. ulmifolia e S. terebinthifolius se destacaram, obtendo um índice mínimo de $66,66 \%$ de resistência ao local e diferindo estatisticamente das demais, que se quer alcançaram $50 \%$ de sobrevivência: L. molleoidesolleoides (40\%), S. pseudoquina (11,11\%), T. sellowiana $(11,11 \%)$ e S. granuloso-leprosum $(6,67 \%)$ (Figura 2H).

\section{DISCUSSÕES}

\subsection{Crescimento e sobrevivência dos modelos de plantio}

A mortalidade de $100 \%$ das espécies E. erytropappus e N. lanceolata em M4 (Figura 1D) permite inferir que elas não se adaptaram ao ambiente proposto, local esse extremamente degradado. Destaca-se que ocorreu no período chuvoso alagamento da área por vários dias devido à alta precipitação pluviométrica entre novembro/ 
2009 e janeiro/2010, totalizando 996,80 mm (Tabela 1), o que pode ser uma das causas da mortalidade das espécies. Estudos realizados por Scolforo et al. (2002) indicaram que a E. erytropappus é adaptada a solos secos, e Lorenzi (2002) descreveu que a N. lanceolata é cultivada em regiões que apresentam precipitação bem distribuída, necessitando de $1.500 \mathrm{~mm}$ anuais, que representam a precipitação ocorrida de novembro/2009 a janeiro/2010 (Tabela 1) $66,45 \%$ de todo o volume de que a espécie precisa ao longo de todo o ano. Ainda,
$N$. lanceolata é exigente de solos férteis (LORENZI, 2002), condição não observada na área com baixos níveis de matéria orgânica $\left(0,21 \mathrm{~g} / \mathrm{dm}^{3}\right)$ e fósforo e valores médios para potássio (Tabela 2), e a altitude da área de 899 m encontra-se no limite inferior do intervalo de adaptação de E. erytropappus, que segundo Scolforo et al. (2002) é de 900 e de $1.700 \mathrm{~m}$.

A certa homogeneidade em $\mathrm{He}$ e $\mathrm{C}$ entre os modelos de plantio M1, M2 e M3 pode estar relacionada ao fato de terem sido plantadas espécies nativas autóctones
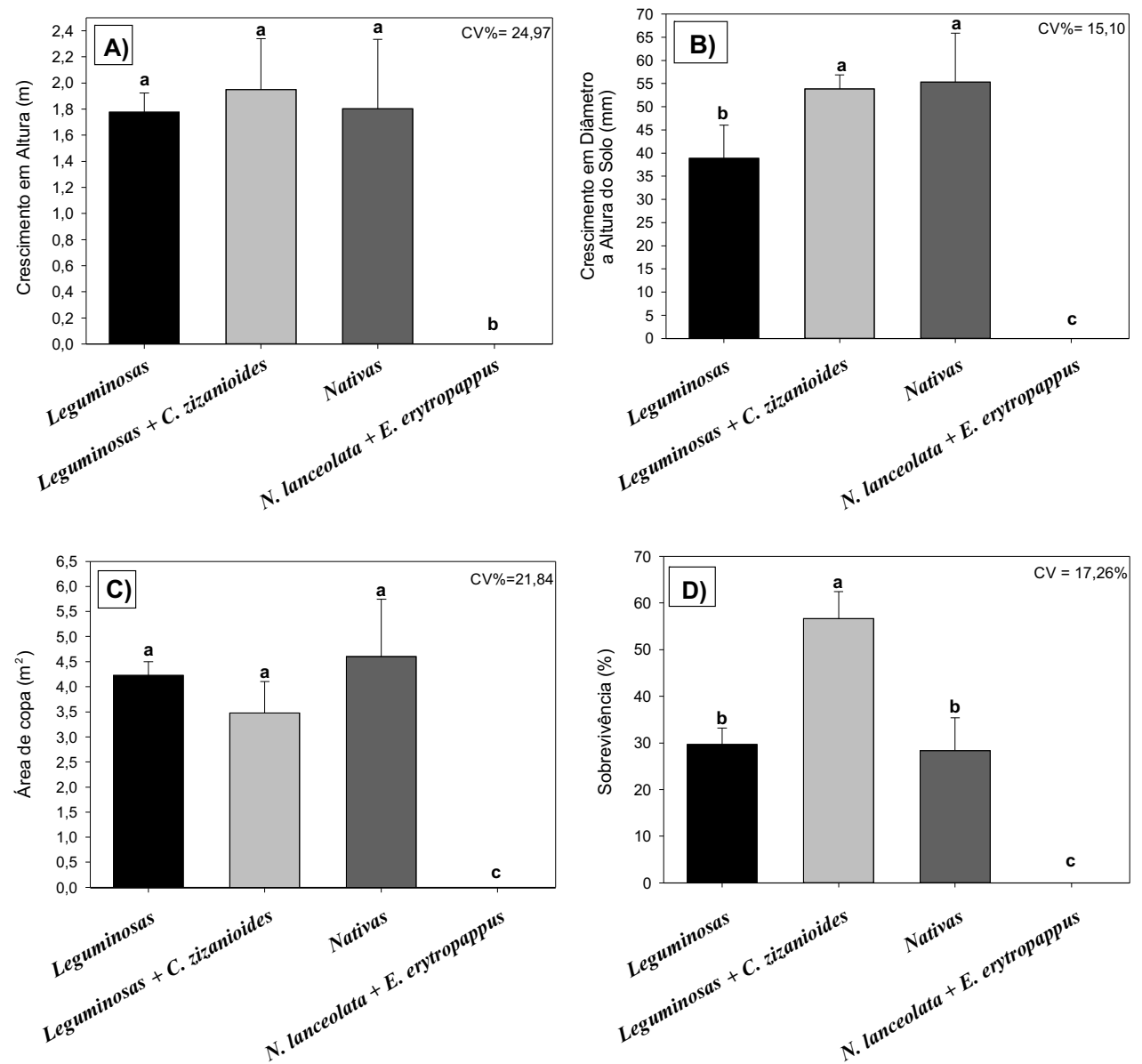

Figura 1 - Parâmetros de crescimento e sobrevivência, aos 20 meses de idade, em diferentes modelos de plantio, em área degradada por disposição de resíduos sólidos urbanos, em Inconfidentes, MG: A) Altura; B) Diâmetro do caule ao nível do solo; C) Área de copa; e D) Sobrevivência. Médias seguidas de mesma letra não diferem significativamente entre si, pelo teste de Scott-Knott a $5 \%$ de probabilidade.

Figure 1 - Growth and survival parameters at age of 20 months in different planting models in area degraded by urban solid waste disposal in Inconfidentes, MG: A) Height; B) Stem diameter on ground level; C) Canopy area; D) Survival. Average values followed by the same letter do not present significant differences among them by the Scott-Knott test, at $5 \%$ probability. 

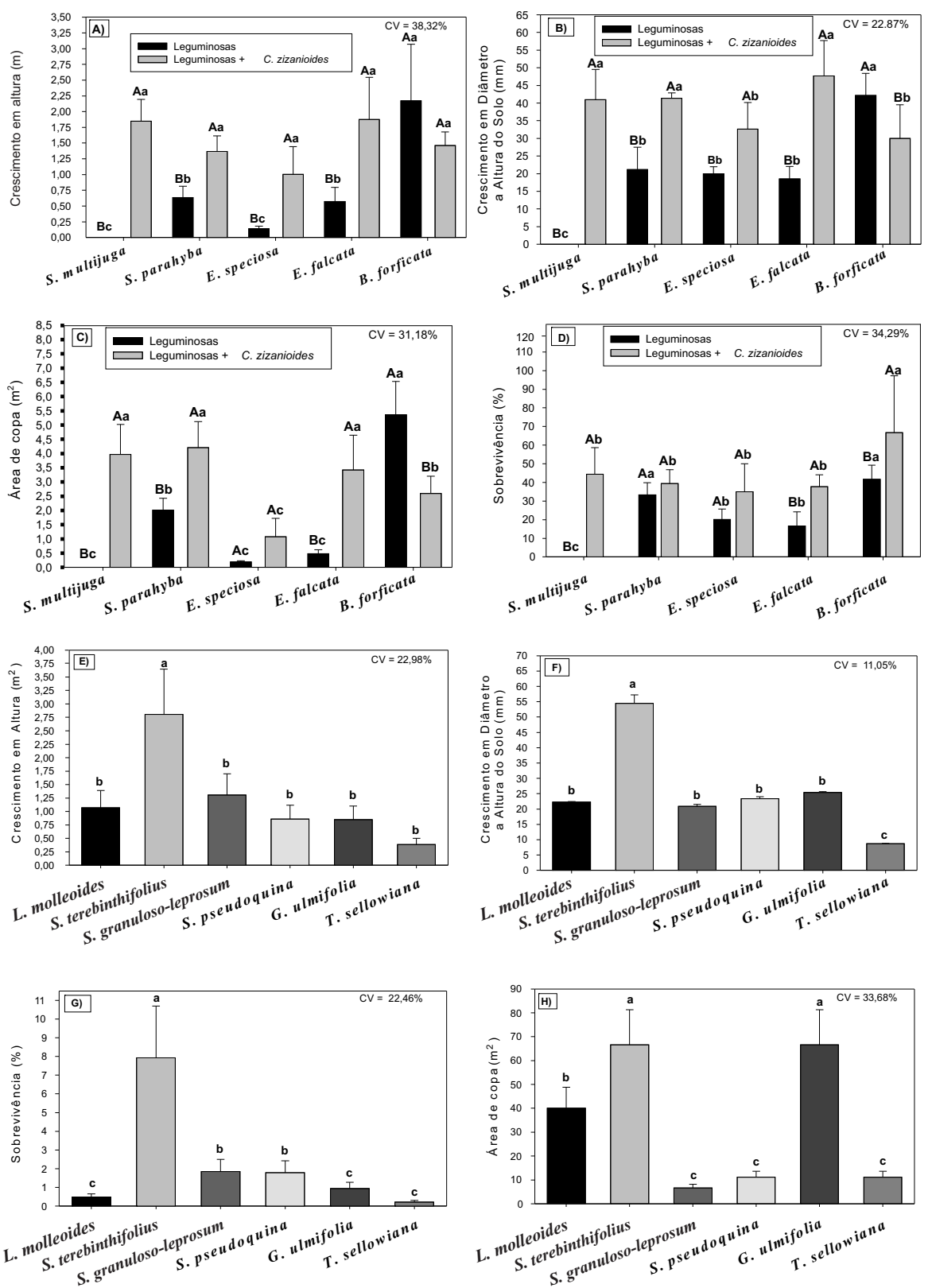

Figura 2 - Crescimento e sobrevivência das espécies, aos 20 meses de idade, nos modelos de plantio M1 (Leguminosas) e M2 (Leguminosas + C. zizanioides): A) Altura; B) Diâmetro do caule ao nível do solo; C) Área de projeção da copa; D) Sobrevivência; e no modelo de plantio M3 (Nativas); E) Altura; F) Diâmetro do caule ao nível do solo; G) Área de copa; e H) Sobrevivência. Médias seguidas pela mesma letra minúscula comparam as espécies dentro de cada modelo de plantio, e as seguidas pela mesma letra maiúscula comparam a espécie entre os modelos de plantios, não diferindo significativamente entre si, pelo teste de Scott-Knott a 5\% de probabilidade.

Figure 2 - Growth and survival of species at age 20 months in the planting models M1 (Legume) and M2 (Legume + C. Zizanioides): A) Height; B) Stem diameter on ground level; C) Canopy area; D) Survival; and in the planting model M3 (Native): E) Height; F) Stem diameter on ground level; G) Canopy area; and H) Survival. Average values followed by the same lower case letter compare the species on each planting model, and the ones followed by the same capital letter compare the species among the planting models and don't present significant differences among them by the Scott-Knott test, at $5 \%$ probability.

Revista Árvore, Viçosa-MG, v.39, n.1, p.147-157, 2015 
e do grupo ecofisiológico das pioneiras, que apresentam comportamento de preenchimento (espécies de rápido crescimento e copa ampla), corroborando os trabalhos de Andrade (2000), que citou que nesses locais se devem priorizar as espécies que contêm características de adaptabilidade, ou seja, nativas do local.

A diferença significativa $(\mathrm{P}>005)$ do modelo de plantio M2 ao M1 nas variáveis DC (Figura 1B) e sobrevivência (Figura 1D) pode ser justificada pelo consórcio da gramínea C. zizanioides em M2. A adoção desse consórcio faz que as espécies se interajam e a gramínea que apresenta bom desenvolvimento em vários espaçamentos de plantio (ANDRADE et al., 2011) e pode apresentar raízes que alcançam até $4 \mathrm{~m}$ de profundidade (PEREIRA, 2006) aumentam a porosidade da superfície do solo. Tal fato contribui para a infiltração da água e a descompactação do solo (SANTOS et al., 2001) e possibilita que as parcelas do M2 não ficassem alagadas, ajudando diretamente a sobrevivência e desenvolvimento em DC das espécies arbóreas.

\subsection{Crescimento e sobrevivência das espécies arbóreas nos diferentes modelos de plantio}

A adaptabilidade superior das espécies no modelo de plantio M2 (Figura 2A-D) pode ser justificada pelo potencial da gramínea $C$. zizanioides, que tem o sistema radicular maciço finamente estruturado, além de profundo, chegando a 4 m (PEREIRA, 2006). Para Cheng et al. (2003), o fato de as raízes dessa gramínea, em sua maioria, serem finos com diâmetro médio de $0,5-1,0 \mathrm{~mm}$ proporciona enorme volume de rizosfera de crescimento e multiplicação de bactérias e fungos, permitindo a absorção de contaminantes e processos de decomposição, como nitrificação, e ajudando no desenvolvimento de outras espécies no local. Segundo Truong et al. (2008), a adoção do consórcio entre as espécies arbóreas e herbáceas é opção viável devido ao fato de as gramíneas promoverem rápida e densa cobertura do solo. Isso além do fato de o estabelecimento das raízes aumentar a porosidade das superfícies do solo, o que contribui para a infiltração da água e pode ter ajudado a prevenir o acúmulo localizado na área e auxiliado no desenvolvimento e sobrevivência das espécies na área moderadamente compactada.

As espécies de leguminosas arbóreas S. multijuga, E. falcata e S. parahyba, que sobressaíram no M2 (Figuras 2A-D), apresentam, segundo Manhago (2008), boa capacidade de melhorar a qualidade dos nutrientes encontrados no solo, através da fixação biológica do nitrogênio em associações simbióticas com fungos micorrízicos e bactérias do gênero Rhizobium, aumentando a eficiência na absorção da água e dos nutrientes em solução por outras plantas que possam vir a se estabelecer por regeneração natural e, ou, para as próprias mudas plantadas. Chada et al. (2004) salientaram que essas associações favorecem o crescimento do DC, sendo de fundamental importância na recuperação de áreas degradadas (RAD). Essas espécies promoveram maior cobertura do solo em função do desenvolvimento da AC (Figura 2C), parâmetro de crescimento importante, segundo Lorenzi (2002), para a seleção de espécies a serem utilizadas na RAD, locais que necessitam de rápido recobrimento para interceptar a chuva, evitando o seu contato direto com o solo e do vento diretamente com o solo exposto.

A altura da espécie $B$. forficata destacou-se ao longo das avaliações mensais (PINTO et al., 2011) entre as leguminosas arbóreas, apresentando maior média geral de altura e não diferindo estatisticamente nos modelo de plantios M1 e M2, sendo indiferente quanto às condições de umidade do solo. Carvalho (1994) e Sousa (2008) relataram que a B. forficata não é exigente quanto às condições edáficas, pois ocorre em quase todos os tipos de solo, além de suportar inundações periódicas de rápida duração.

A diferença observada entre as espécies plantadas no modelo de plantio M3 em todos os parâmetros de crescimento avaliados e na sobrevivência (Figura 2E$\mathrm{H})$ pode ser justificada pela exigência nutricional bastante distinta entre as espécies, mesmo pertencendo ao mesmo grupo ecológico, pioneira, e sendo autóctone. A Tabela 1 expõe as condições nutricionais das análises de solo realizadas durante a pesquisa, em que se destacam baixos níveis de fósforo e matéria orgânica e valores médios para potássio, condições de fertilidade que, segundo Costa e Zocche (2009) e Rodrigues et al. (2007), inibe o desenvolvimento das espécies.

A espécie S. terebinthifolius apresentou bom desenvolvimento em AC, resultado desejado para a recuperação de qualquer área degrada, pois, quanto maior a AC, melhor o recobrimento do solo exposto, diminuindo a capacidade de lixiviação de minerais e a ocorrência de erosões (SOUZA, 2007). Para Beemster et al. (1996 citados por GUIMARÃES et al., 2002), o grau de compactação do solo pode afetar a parte aérea 
das espécies, diminuindo-lhes a área foliar e, consequentemente, a AC. Assim, uma das justificativas do baixo desenvolvimento da AC das espécies no experimento foi devida à compactação da área $(0,59$ Mpa), classificada como intermediária segundo USDA (1993), compactação essa advinda da exposição da área, por vários anos, à atividade que utilizava grandes maquinários. O bom desempenho de S. terebinthifolius na área em recuperação se deve, segundo Mielke et al. (2004), à facilidade que tem de se desenvolver em área com inundações periódicas, apresentar crescimento rápido nos primeiro anos de vida e por ser rústica, desenvolvendo-se também em terrenos secos e pobres em nutrientes.

As espécies L. molleoides, S. granuloso-leprosum, S. pseudoquina, G. ulmifolia e T. sellowiana, apesar de pertencerem ao grupo ecológico das pioneiras, não apresentaram bom desenvolvimento nos parâmetros de crescimento avaliados (Figura 2E-G). Carvalho (1994) relatou que algumas espécies não se desenvolvem bem em H e DC quando há ocorrência de seca. Como a região é de clima tropical úmido, com duas estações definidas, chuvosa e seca, na estiagem de abril a setembro, totalizando $171,4 \mathrm{~mm}$, as espécies podem ter sofrido e tido como efeito negativo o baixo crescimento em $\mathrm{H}$ e DC.

A diferença estatística observada na sobrevivência entre as espécies nos diferentes modelos de plantio (Figura 2DH) indica que há espécies mais resistentes e adaptadas às condições de baixa fertilidade (Tabela 2), de compactação intermediária (0,59 Mpa), climáticas e com a presença de chorume ácido $(\mathrm{pH}=5,86)$ no período de avaliação (Tabela 1). Andrade (2005) ressaltou que em aterros a decomposição anaeróbia da matéria orgânica gera gases e chorume, que são tóxicos para algumas plantas utilizadas para recuperação do local, ocorrendo, então, a sua mortalidade.

A ausência de sobrevivência da espécie S. multijuga no modelo de plantio M1 contrasta com o percentual moderado de sobrevivência (44\%) apresentado no modelo de plantio M2, percentual que não diferencia da sobrevivência das leguminosas S. parahyba, E. speciosa e E. falcata (Figura 2D). Segundo Lorenzi (2002), a espécie adapta-se a diversos tipos de solos e é indicada para RAD, no entanto essa boa adaptação não ocorreu no modelo de plantio M1, podendo estar associada ao contato direto que a espécie teve com o chorume ácido $(\mathrm{pH}=5,86)$, principalmente na época em que ocorreu alagamento pela alta taxa de precipitação em janeiro e fevereiro de 2011 (Tabela 2). Esse alagamento não se deu no modelo de plantio M2 em razão da presença da gramínea C. zizanioides, auxiliando na sobrevivência da espécie.

Os melhores percentuais de sobrevivência no modelo de plantio M3 foram das espécies S. terebinthifolius e G. ulmifolia, com $66,66 \%$, diferindo estatisticamente de L. molleoides (40\%), S. pseudoquina (11,11\%), T. sellowiana $(11,11 \%)$ e S. granuloso-leprosum $(6,67 \%)$ (Figura 2H). Para Caron (2007), a espécie S. terebinthifolius tem sido recomendada para os locais degradados, pois é considerada espécie rústica, suportando condições ambientais extremas. Essa sobrevivência corrobora as afirmações de Carvalho (1994), que salientou que a espécie tem facilidade para se instalar em áreas com inundações periódicas de rápida duração e com período de encharcamento moderado. A espécie G. Ulmifolia para diversos autores (FELFILI, 2000; LORENZI, 2002; LIMA et al., 2009b) é considerada pioneira altamente resistente às condições de grande luminosidade e com boas características de desenvolvimento, sendo qualificada como importante para a RAD. Mesmo sendo indicadas para a RAD, as espécies S. pseudoquina e S. granuloso-leprosum, que se adaptam a ambientes secos e solos drenados (LORENZI, 2002); L. molleoides, por se adaptar a solos com baixa fertilidade e com alta toxidez (BARROS et al., 2007); e T. Sellowiana, por ser rústica e heliófita, características favoráveis para implantação nos locais de solo pobre (LORENZI, 2002), apresentaram baixo percentual de sobrevivência. Esse fato pode estar relacionado às condições extremas a que a área foi submetida, altos índices pluviométricos em curto período do ano (dezembro/2010 a março/2011), totalizando 1.073,9 $\mathrm{mm}$ em apenas quatro meses consecutivos e um período de seca (abril a setembro/2011), totalizando apenas 171,4 mm, em seis meses (Tabela 1). No período chuvoso, a área esteve alagada por vários dias, condições que, segundo Lorenzi (2002), não são favoráveis às espécies da família Solanaceae (S. pseudoquina e S. granulosoleprosum), que não são tolerantes a solos úmidos.

\section{CONCLUSÃO}

Ao avaliar o crescimento silvicultural e a sobrevivência das 13 espécies arbóreas aos 20 meses de idade em diferentes modelos de plantio implantados 
para requalificar a área do antigo depósito de RSU do Município de Inconfidentes, MG, concluiu-se que:

O modelo de plantio M2 (leguminosas $+C$. zizanioides) deve ser utilizado para recuperação do restante da área do antigo depósito de RSU do Município de Inconfidentes, MG, por ter promovido maior sobrevivência $(56,6 \%)$ e destacado crescimento das espécies nos parâmetros altura $(\mathrm{H})$, diâmetro do caule ao nível do solo (DC) e área de copa (AC).

O consórcio da gramínea Vetiver com as leguminosas arbóreas favoreceu a sobrevivência das leguminosas arbóreas, em especial da espécie S. multijuga, que apresentou $44 \%$ de sobrevivência no modelo de plantio M2 (leguminosas $+C$. zizanioides), enquanto no modelo de plantio M1 (leguminosas) a mortalidade foi de 100\%, além de ter promovido melhor crescimento em H, DC e AC.

As espécies Bauhinia forficata, Eritrina falcata, Senna multijuga, Schizolobium parahyba e Schinus terebinthifolius foram as que apresentaram melhor crescimento em H, DC, AC e sobrevivência, sendo viável o estabelecimento delas em ambientes com condições ambientais iguais/semelhantes da área estudada.

\section{AGRADECIMENTOS}

Ao CNPq, pelos recursos financeiros para a execução do projeto "Revegetação de Áreas de Lixões por Diferentes Técnicas de Regeneração Artificial”; e ao IFSULDEMINAS - Câmpus Inconfidentes, pela concessão da bolsa e equipamentos complementares.

\section{REFERÊNCIAS}

ALBERTE, E. P. V.; CARNEIRO, A. P.; KAN, L. Recuperação de áreas degradadas por disposição de resíduos sólidos urbanos. Diálogos e Ciência - Revista Eletrônica da Faculdade de Tecnologia e Ciências de Feira de Santana, v.3, n. 5, p.1, 2005.

ANDRADE, J. C. M. Vegetação em aterros sanitários de resíduos sólidos urbanos: estudo de caso do aterro sanitário de Santo Amaro, São Paulo. 2000. 186 f. (Tese de doutorado em ciência da engenharia civil). - COPPE/UFRJ, Rio de Janeiro, 2000.

\author{
ANDRADE, J. C. M. Fitotransporte de \\ metais em espécies arbóreas e \\ arbustivas em aterro de resíduos \\ sólidos urbanos Rio de Janeiro: 2005. 263p.
}

ANDRADE, J. C. M. E.; MAHLER, C. F. Adaptability of tree plants and shrubs in urban landfills: a case study. In: INTERNATIONAL WASTE MANAGEMENT AND LANDFILL SYMPOSIUM, 8., 2001, Cagliari. Proceedings... Cagliari: CISA Environmental Sanitary Engineering Centre, 2001. v.4. p.419426.

BARROS, D. L.; SILVA, F; FERREIRA, R. R. M.; FERREIRA, V. M. Avaliação das espécies vegetais em condições adversas na estabilização de voçorocas no município de Nazareno (MG). In: Congresso Brasileiro de Ciência do Solo, 31., 2007, Gramado, RS.

Anais... Gramado: 2007.

BELI, E.; NALDONI, C. E. P.; OLIVEIRA, A. C.; SALES, M. R.; SIQUEIRA, M. S. M; MEDEIROS, G. A.; HUSSAR, G. J.; REIS, F. A. G. V.

Recuperação da área degradada pelo lixão Areia Branca de Espírito Santo o Pinhal, SP.

Engenharia Ambiental (Online), v. 2, n.1, p. $135-148,2005$

CARON, B. O. Análise de crescimento de plantas de Aroeira Vermelha no Município de JiParaná-RO. Revista da FZVA, v.14, n.1, p.1, 2007.

CARVALHO, P. E. R. Espécies florestais brasileiras: recomendações silviculturais, potencialidades e uso de madeira. Colombo: Embrapa-SPI, 1994. 639p.

CHADA, S. S.; CAMPELLO, E. F. C.; FARIA, S. M. Sucessão vegetal em uma encosta reflorestada com leguminosas arbóreas em Angra dos Reis, RJ. Revista Árvore, v.28, n.6, p.801-809, 2004.

CHENG, H.; YANG, X.; LIU, A.; FU, H.; WAN, M. A Study on the performance and mechanism of soil-reinforcement by herb root system. In: INTERNATIONAL VETIVER CONFERENCE GUANGZHOU, 3., 2003, China. Proceedings...China: 2003.

Revista Árvore, Viçosa-MG, v.39, n.1, p.147-157, 2015 


\section{COMPANHIA DE SANEAMENTO DE MINAS GERAIS - COPASA. Coleta de dados pluviômetros. Inconfidentes: 2012.}

COSTA, S.; ZOCCHE, J. J. Fertilidade de solos construídos em áreas de mineração de carvão na região sul de Santa Catarina. Revista Árvore, v.33, n.4, p. 665-674, 2009 .

FELFILI, J. M.; RIBEIRO, F. J.; FAGG, C. W.; MACHADO, J. W. B. Cerrado: manual para recuperação de Matas de Galeria. Planaltina: Embrapa Cerrados, 2000. 45p. (Documentos/ Embrapa Cerrados, n.21)

FERREIRA, W. C.; BOTELHO, S.; DAVIDE, A. C.; FARIA, J. M. R. E FERREIRA, D. F. Regeneração natural como indicador de recuperação de área degradada a jusante da usina hidrelétrica de Camargos, MG. Revista Árvore, v.34, n.4, p. 651-660, 2010 .

GUIMARÃES, C. M.; STONE, L. F.; MOREIRA, J. A. A. Compactação do solo na cultura do feijoeiro. II: efeito sobre o desenvolvimento radicular e da parte aérea. Revista Brasileira de Engenharia Agrícola Ambiental, v.6, n.2, p. 213-218, 2002.

\section{INSTITUTO BRASILEIRO DE GEOGRAFIA E} ESTATÍSTICA - IBGE. Pesquisa Nacional de Saneamento Básico (PNSB) - 2008. Rio de Janeiro: 2010. 60p.

LIMA, J. A.; SANTANA, D. G.; NAPPO, M. E. Comportamento inicial de espécies na revegetação da mata de galeria na Fazenda Mandaguari, em Indianópolis, MG. Revista Árvore, v.33, n.4, p.685-694, 2009.

LIMA, R. ; INOUE, M. T. ; SAMPIETRO, J. A. ; PEREIRA, A. L. N. ; BLUM, H. . Avaliação da regeneração natural para recuperação de área degradada por aterro sanitário na região centrosul do Paraná. In: Semana de Estudos de Engenharia Ambiental, 7., 2009, Irati. Anais...Guarapuava: UNICENTRO, 2009. v. 1.

LONDE, P. R.; BITAR, N. A. B. Importância do uso de vegetação para contenção e combate à erosão em taludes do lixão desativado no municipio de Patos de Minas (MG). Perquirere, v. 8, p. 224-249, 2011.
LORENZI, H. Árvores brasileiras: manual de identificação e cultivo de plantas arbóreas nativas do Brasil. Nova Odessa: Plantarum, 2002. v.1.368p.

MANHAGO, R. S. Técnicas de revegetação de Talude de Aterro Sanitário.

Seropédica/RJ: Universidade Federal Rural do Rio de Janeiro-Instituto de Florestas Curso de Engenharia Florestal. 2008.

MIELKE, M.S.; ALMEIDA, A. A.F.; GOMES, F.P.; MANGABEIRA, P.A.O.; SILVA, D.C. Effects of soil flooding on leaf gas exchange and growth of two neotropical pioneer tree species. New Flores. v.29, p.161-168. 2005.

PEREIRA, A. R. Como selecionar plantas para áreas degradadas e controle de erosão. Belo Horizonte: Deflor bioengenharia, 2006. 88 p.

PINTO, L. V. A. ; RESENDE, L. A. ; ALBINO, N. G. ; COUTO, R. Sobrevivência de espécies arbóreas nos períodos seco e chuvoso em área de lixão. In: CONGRESSO NACIONAL DE MEIO AMBIENTE, 8., 2011. Poços de Caldas. Anais... Poços de Caldas: 2011. CD-ROM.

RODRIGUES, L. A.; CARVALHO, D. A.; OLIVEIRA FILHO, A.T.; CURI, N. Efeitos de solos e topografia sobre a distribuição de espécies arbóreas em um fragmento de floresta Estacional Semideciodual em Luminárias, MG. Revista Árvore, v.1, n.1, p.25-35, 2007.

SANTOS, A. C.; SILVA, I. F.; LIMA, J. R. S.; ANDRADE, A. P.; CAVALCANTE; V. R. Gramíneas e leguminosas na recuperação de áreas degradadas: efeito nas características químicas de solo. Revista Brasileira de Ciência do Solo, v.25, n.4, p.1063-1071, 2001.

SCOLFORO, J.R.S.; OLIVEIRA, A.D.; DAVIDE, A.C.; MELLO, J.M.; ACERBI JUNIOR, F.W.

Manejo sustentável da candeia

Eremanthus erythropappus e Eremanthus incanus. Lavras: UFLA/FAEPE, 2002. 350p. (Relatório Técnico Científico)

SOUSA, J. V. Desenvolvimento inicial de leguminosas arbóreas nativas em várzea sob diferentes condições de 
drenagem na regeneração de matas ciliares. 2008. 80f. Dissertação (Mestrado em Gestão de Recursos Agroambientais) - PósGraduação - IAC, Campinas, 2008.

SOUZA, C. M. Recuperação de áreas degradadas em aterros sanitários. Seropédica: Universidade Federal Rural do Rio de Janeiro, 2007. (Monografia ao curso de
Engenharia Florestal no Instituto de Florestas da Universidade Federal Rural do Rio de Janeiro)

TRUONG, P. N.; VAN TAN, T.; PINNER, E. Sistema de aplicação vetiver: Manual de referência técnica. 2.ed. Vietnam: 2008. 116p.

USDA. Soil survey manual. Washington, DC: Soil Survey Division Staff, 1993. 437p. (Handbook, 18) 